\title{
RESERVA LEGAL ÀS MARGENS DE CURSO D'ÁGUA NAS CIDADES BRASILEIRAS: PRESERVAÇÃO E PROTEÇÃO DE UM ECOSSISTEMA
}

\author{
Saulo Ferraz Alves Medeiros \\ Bacharel em Arquitetura e Urbanismo - Universidade Presbiteriana Mackenzie - 2002; Servidor \\ Efetivo da Prefeitura do Município de São Paulo - 2006; Especialista em Gestão Ambiental - \\ Universidade Nove de Julho - 2010; Especialista em Habitação e Cidade - Faculdade de Arquitetura \\ e Urbanismo Escola da Cidade - 2011; E-mail: saulomedeiros@hotmail.com
}

\begin{abstract}
Resumo
Qual a relação entre reserva legal às margens de curso d'água nas cidades brasileiras e o meio antrópico? Restringimos-nos a tratar o ecossistema à margem de cursos d'água em área urbana dentro do território nacional, analisando normas legais e aspectos ecológicos relacionados ao problema de pesquisa. Por hipótese, os corredores verdes nas cidades são focos de qualidade da vida humana, sob diversos aspectos, diretos e indiretos, consequência da preservação e proteção da biota. Tomamos a qualificação urbanística sob a ótica ambiental, com a conservação dos recursos naturais em área urbana, quebrando o paradigma da canalização de rios, córregos e uso de margens exclusivamente voltado para o sistema viário. O método de trabalho foi baseado na revisão teórica das referências bibliográficas. Os resultados obtidos corroboram com a hipótese gerada de que a reserva legal às margens de curso d'água nas cidades brasileiras influenciam positivamente o desenvolvimento sustentável do ecossistema urbano.
\end{abstract}

Palavras chave: Legislação Ambiental e Urbanística; Conservação dos Recursos naturais; Sustentabilidade; Parque Linear; Bacia Hidrográfica. 


\title{
LEGAL RESERVE ON THE BANKS OF WATERCOURSE IN BRAZILIAN CITIES: PRESERVATION AND PROTECTION OF AN ECOSYSTEM
}

\begin{abstract}
What is the relationship between legal reserve on the banks of waterway in Brazilian cities and the human environment? We restrict ourselves to treat the ecosystem at the edge of waterways in urban areas within the national territory, analyzing the legal and ecological aspects related to the research problem. By hypothesis, green corridors in cities are hotbeds of quality of human life, in many ways, direct and indirect consequence of the preservation and protection of biota. We qualifying urban environment from the ambient perspective, with conservation of natural resources in urban areas, breaking the paradigm of the canalization of rivers, streams and use of banks exclusively focused on the road system. The working method was based on a review of theoretical references. The results corroborate the hypothesis that generated the legal reserve on the banks of waterway in Brazilian cities positively influence the development of sustainable urban ecosystem.
\end{abstract}

Keywords: Environmental Law and Urban Planning; Conservation of Natural Resources; Sustainability; Linear Park; Hydrographic Basin.

\section{APRESENTAÇÃO}

O ser humano depende de serviços ambientais como condição para sua sobrevivência. Para facilitar a ocorrência destas condições foram criados os aglomerados humanos. Na verdade, foi a partir da formação dos aglomerados urbanos que as relações ser humano e natureza se tornaram mais complexas.(DIAS, 2004, p. 249)

Na verdade, o ecossistema urbano é um meio ambiente artificializado por ação humana, porém, conectado ao meio ambiente natural, mantendo um certo equilíbrio entre si, como ocorre em outros ecossistemas. As modificações antropomórficas não eximem os habitantes do meio ambiente urbano do cuidado com os recursos naturais, tendo em vista a escassez dos mesmos, pois sabemos que a Terra não pertence ao homem; o homem pertence à Terra. Sabemos que todas as coisas estão ligadas como o sangue que une uma família.(ANEXO 9. In: DIAS, 2004, p. 516) 
Desse modo, notamos que as noções de dependência do ser humano e da natureza foram observadas nas civilizações mais primitivas, entretanto, hoje, muitos habitantes das grandes cidades do mundo parecem que se esqueceram de que não tecemos 0 tecido da vida, somos simplesmente um de seus fios. Tudo o que fizermos ao tecido faremos a nós mesmo.(ANEXO 9. In: DIAS, 2004, p. 516)

No Brasil, as áreas de terreno permeáveis e alagáveis encontradas às margens de curso d'água foram entendidos como obstáculos ao perfeito desenvolvimento das cidades, pelo menos na maioria dos processos de urbanização. Como característica presente na urbanização brasileira, podemos citar a implantação de avenidas nas margens dos cursos d'água, substituindo a mata ciliar por vias impermeabilizadas. (LUCAS, 2009, p. 22)

Segundo especialistas, a história do urbanismo brasileiro originou-se de práticas oriundas dos povos Ibéricos, para os quais a ocupação dos topos de morro, das áreas ciliares e várzeas era uma situação mais do que normal, e determinada segundo os padrões urbanísticos e sanitários da era medieval e moderna.(MIRANDA, 2008, p. 1)

Historicamente, as cidades brasileiras que sofreram maior influência lbérica em sua colonização, promoveram a ocupação do solo com suas casas construídas às margens dos rios, e de costas para eles, escondendo-o da paisagem, reforçando a idéia de insalubridade dos mesmos.(MIRANDA, 2008, p. 1)

Entretanto, os prejuízos desta concepção de cidade são sentidos hoje, de forma direta, pelas populações que convivem com as enchentes, e de forma indireta afetam negativamente aspectos econômicos, sociais e culturais das cidades. A impermeabilização do solo viria a se tornar sinônimo de salubridade e de desenvolvimento social para as cidades brasileiras, com a ajuda do carro, cuja presença estava ligada ao progresso econômico. Entretanto, os diversos males desta prática seriam crescentes na mesma proporção das cidades.

Após quinhentos anos de ocupação, urbana e rural em áreas de várzeas, há apenas vinte anos temos uma legislação ambiental restritiva. Esta tardou a acompanhar o pensamento de preservação do meio ambiente e na maioria dos casos incentivou à ocupação de margens de rios e córregos em nome da salubridade. Trata-se de um 
paradoxo, porque sabendo que a impermeabilização do solo poderia causar de um número maior de enchentes e conseqüentes problemas de saúde para população. (MIRANDA, 2008, p. 1)

O município de São Paulo desempenhou um papel importante no processo de urbanização de outras cidades do território nacional, isto porque, tendo em vista seu papel na economia do país e importância que se dá ao aspecto econômico, suas política públicas serviram de exemplo para outras cidades. Em 1929, a implantação do Plano de Avenidas, que teve início durante a administração de Prestes Maia, foi um Plano modelo em que a política de eficiência na circulação, baseado no sistema radio-concêntrico de vias arteriais, torna-se-ia sinônimo de modernidade e salubridade.(LUCAS, 2009, p. 22)

O Plano Urbanístico Básico, ocorrido em 1969, viria a reafirmar a importância das avenidas de fundo de vale, por seu baixo custo e topografia suave, como suporte para o sistema viário na cidade, embora não mais apoiado no sistema radio-concêntrico. (LUCAS, 2009, p. 23)

A impermeabilização crescente de margens de cursos d'água e fundos de vale urbanos resultante destes planos agravou o quadro de enchentes na cidade. Citando a região do Aricanduva, as cheias trouxeram prejuízo não apenas às populações ribeirinhas, mas também as linhas do Metrô e CPTM que passam pela região, trazendo prejuízos econômicos, além de problemas de saúde.(LUCAS, 2009, p. 23)

Outras cidades pelo Brasil seguiram o exemplo de São Paulo, com a ambição de acompanhar o desenvolvimento econômico do país, contudo, o que se viu desde então, foi à ocupação de Áreas de Preservação Permanente e fundos de vale pelo sistema viário como prática comum na maioria das cidades.(LUCAS, 2009, p. 22)

A retificação e canalização de rios ganharam, desde então, status de modernidade e salubridade. Entretanto, o inevitável agravamento das enchentes, logo começar a incomodar os habitantes que convivem freqüentemente com o problema. Mesmo com a ocorrência freqüente de enchentes, as políticas públicas continuam voltadas às obras de canalização, retificação de rios e córregos, construção de pontes e viadutos e incentivo ao transporte individual motorizado. Com a crescente educação ambiental, começamos a tomar condições de cobrar atitudes coerentes com o desenvolvimento sustentável. 
Hoje temos plena consciência de que todo desenvolvimento que vise uma economia de curto, médio e longo prazo deverá partir de fatores de equilíbrio ambiental, uma vez que a grande maioria dos desastres na natureza, provocados pelo homem, ocorrem em decorrência da práxis econômica do lucro rápido e fácil, fruto de uma sociedade oposta à natureza, construída por muitas gerações, resultado de uma política urbana que vem de muitos anos, baseada na construção de pontes, viadutos e piscinões. (FRANCO, 1997, p. 133)

\section{O ECOSSISTEMA ÀS MARGENS DE CURSO D'ÁGUA}

Os fundos de vale são áreas naturalmente alagáveis ao longo de curso d'água que promovem o equilíbrio responsável pela manutenção deste ecossistema. As florestas encontradas nestas regiões possuem nomenclatura variada, entre elas a mais aceita é mata ciliar, cuja definição técnica da biologia veremos a seguir:

Existem varias definições sobre a mata ciliar.[...] Fitoecologicamente falando, trata-se de toda a formação florestal que se encontrar às margens de cursos d'água, independentemente de sua área ou região de ocorrência e de sua composição florística. Em se tratando do território brasileiro, este conceito de florestas ou matas ciliares acaba tendo uma abrangência enorme, quase que total, já que podem ser encontradas, de uma forma ou de outra, em todos os domínios morfoclimáticos e fitogeográficos do país.

Esse tipo de vegetação ocorre nas porções de terreno que incluem tanto a ribanceira de um rio, como também as superfícies de inundação, indo até às margens do corpo d'água (YANG, 2005, p. 7)

A preservação e proteção da mata ciliar no contexto urbano são tão importantes ou até mais importante que em área rural, tendo em vista que a simples existência deste ecossistema colabora para limpeza dos cursos d'água, controle de cheias, controle com clima e da temperatura, controle da umidade do ar, controle da expansão urbana, remoção de impurezas do ar, além de melhorar a paisagem do ambiente urbano colaborando beneficamente com aspectos culturais e econômicos da cidade. 
Além disso, do ponto da bacia hidrográfica, a mata ciliar também tem uma função importante. O fundo de várzea urbano, ou seja, a porção do terreno que inclui a ribanceira do rio, a planície de inundação, com suas condições de solo próprias e a vegetação que nesta região ocorre, é um sistema que funciona como regulador do fluxo de água, sedimentos e nutrientes entre os terrenos mais altos da bacia hidrográfica e $o$ ecossistema aquático.(YANG, 2005, p. 9)

Também devemos considerar que o fator psicológico da existência de uma mata ciliar e da preservação e proteção das margens do curso d'água em área urbana exerce sobre as pessoas, colaborando para formação de uma cultura voltada para os princípios de conservação dos recursos naturais. Do contrario, a canalização de rios diminui importância da natureza em relação aos demais valores humanos.

Além desses fatores esse tipo de vegetação também contribui para a geração do escoamento direto, ou seja, o volume de água que causa o aumento rápido da vazão de microbacias durante e imediatamente após a ocorrência de uma chuva.

A vegetação ciliar contribui também para o aumento da capacidade de armazenamento da água na bacia ao longo da zona ripária, o que contribui para o aumento da vazão na estação seca do ano.

Não se pode esquecer também da importância que a mata ciliar tem no controle da qualidade da água influenciando diretamente.

(YANG, 2005, p. 10)

Hoje, podemos dizer que a preservação e proteção da mata ciliar nos fundos de vale urbanos começam como uma preocupação ecológica de manutenção da flora e da fauna, mas acaba, consequentemente, beneficiando o ser humano que depende de um meio ambiente equilibrado para sobreviver.

\section{CONCEITOS FUNDAMENTAIS: FAIXA NON AEDIFICANDI E ÁREA DE PRESERVAÇÃO PERMANENTE}

O Código de Águas, Decreto $n^{\circ} 24.643$, de 10 de julho de 1934, foi o primeiro instrumento jurídico que legislou sobre as faixas ao longo de cursos d'água, entretanto tratava-se de reserva de Faixa non aedificandi, não possuindo cunho de proteção do meio ambiente, mas apenas de manutenção e acesso aos cursos d'água. 
O objetivo do Código seria, portando, voltado para questões administrativas, como a criação de servidões de trânsito às margens de cursos d'água navegáveis, para as quais estipulava uma faixa de quinze metros, ou não navegáveis, de dez metros. Há o estabelecimento de faixas não edificáveis, mas as mesmas não estavam vinculadas à proteção das matas ciliares.(LUCAS, 2009, p. 32)

Em 1979, o Governo Federal editou a importante sobre legislação sobre o Parcelamento do Solo Urbano, servindo de referencia para os novos loteamentos e desmembramentos que surgissem a partir de então. Com relação à faixa marginal a cursos d'água a Lei Federal $n^{\circ} 6.766$, de 19 de dezembro de 1979, estabeleceu em seu artigo $4^{\circ}$ faixa non aedificandi de 15 metros ao longo de cada margem.(LUCAS, 2009, p. 35).

Entretanto, observamos na mesma Lei que a Faixa non aedificandi não exigível apenas para curso d'água, mas também pode ser reservados às margens de uma ferrovia, duto, canalização, rodovia, área de interesse público, etc. Assim sendo, a imposição é ato administrativo do Poder Público que deve ser respeitado pelo proprietário de um terreno, seja privado ou público, com simples objetivo de guardar acesso a um local de interesse público, para manutenção do mesmo, sem avançar em qualquer conceito de preservação ou proteção ambiental.

Assim, podemos afirmar que o objetivo da criação dessas faixas não edificáveis nem de longe possuem o condão de proteção ambiental, mas simplesmente de ação administrativa de limpeza dos corpos hídricos, de ações emergenciais, e sanitárias.(MIRANDA, 2008, p. 3)

Quanto à semântica do termo Faixa non aedificandi: Faixa é um pedaço longo e estreito de terreno, ou seja, possui comprimento maior em relação a sua largura (HOUAISS, 2001, p. 1300); "Non é a negação do modo da realidade, do indicativo e da oração principal, sendo, entretanto, também encontrada antes do subjuntivo com valor condicional" (FARIA, 2001, p. 223); Aedifico significa construir, edificar; aedificium, edifício, casa; aedificatio, construção, edificação, ato de construir; aedificator, construtor, edificador.(FARIA, 2001, p. 5)

Contudo, o termo non aedificandi é uma expressão latina que poderíamos traduzir como vedado edificar. Entendemos que o conceito legal de Faixa non aedificandi é um ato administrativo proibitivo apenas quando ao direito de edificar num pedaço de terreno de um proprietário qualquer. 
Por outro lado, o conceito de Área de Preservação Permanente foi introduzido a partir do Novo Código Florestal, Lei no 4.771, de 15 de setembro de 1965, que substitui o primeiro Código Florestal Brasileiro, Decreto $n^{\circ} 23.793$, de 23 de janeiro de 1934, do Governo Provisório de Getúlio Vargas.

O Novo Código Florestal de 1965 é mais detalhado que o Código de 1934, não só em relação às definições das faixas, mas também em suas especificidades. Defini-se como Área de Preservação Permanente as matas ciliares localizadas às margens de cursos d'água, por sua função de proteção dos corpos d'água, prevenindo, entre outros, erosão e assoreamento. No entanto, na redação original as faixas eram menos restritivas que as atuais, a partir de cinco metros. A expressão Área de Preservação Permanente passou a ser utilizada no texto legal, embora algumas áreas não possuíssem delimitação de faixa expressa na lei.(LUCAS, 2009, p. 34)

O Código Florestal de 1965 sofreu importantes alterações, especialmente com a edição da Lei no 7.511 , de 7 de julho de 1986, que amplia as Áreas de Preservação Permanente, a partir de trinta metros, sendo mais coerente com a proteção e preservação das matas ciliares e áreas de fundo de vale; a Lei ${ }^{\circ} 7.803$, de 18 de julho de 1989, que inclui as áreas urbanas como aplicáveis na reserva de Área de Preservação Permanente e define que as faixas de proteção deveriam ser marcadas a partir do nível mais alto do curso d'água; a Medida Provisória n².166-67, de 24 de agosto de 2001, que acrescenta o conceito de que não seria necessária a presença de floresta alguma para que as margens de um curso d'água fosse considerada Área de Preservação Permanente.

A partir dessa importante definição da Medida Provisória n 2.166-67, a utilização do argumento de que grande parte das faixas marginais a cursos d'águas localizadas em área urbana consolidada não poderia ser definida como Área de Preservação Permanente, já que não haveria vegetação a preservar, ou seja, a Área de Preservação Permanente estaria descaracterizada pela simples ausência de vegetação, deixou de encontrar amparo legal, tornando-se obrigatória a reserva em quaisquer circunstâncias.(LUCAS, 2009, p. 38) 
A Medida Provisória $n^{\circ}$ 2.166-67 define no seu primeiro artigo, para todos os efeitos do Código Florestal o termo Área de Preservação Permanente como aquela área "coberta ou não por vegetação nativa, com a função ambiental de preservar os recursos hídricos, a paisagem, a estabilidade geológica, a biodiversidade, o fluxo gênico de fauna e flora, proteger o solo e assegurar o bem-estar das populações humanas".

Quanto à semântica do termo Área de Preservação Permanente: Área é uma "extensão mais ou menos limitada de espaço, território ou superfície" (HOUAISS, 2001, p. 281); Preservação é o "ato ou efeito de preservar [...] série de ações cujo objetivo é garantir a integridade e a perenidade de algo; defesa, salvaguarda, conservação" (HOUAISS, 2001, p. 2292); Permanente é aquilo "que permanece no tempo; duradouro, estável [...] que é definitivo”.(HOUAISS, 2001, p. 2192)

Concluímos que Área de Preservação Permanente é uma extensão, mais ou menos limitada de um terreno, seja público ou privado, que deve ser preservada de modo definitivo para conservação da fauna e da flora, cujo objetivo é garantir o equilíbrio de ecossistemas.

Neste ponto do presente estudo faz-se interessante mencionar o artigo quarto da Lei Federal $n^{\circ} 6.766$, de 19 de dezembro de 1979, que exige "ao longo das águas correntes e dormentes e das faixas de domínio público das rodovias e ferrovias, será obrigatória a reserva de uma faixa não edificável de 15 (quinze) metros de cada lado, salvo maiores exigências da legislação específica", fazendo ressalva explícita quanto a maiores exigências estabelecidas por legislação específica. Desse modo é inquestionável a aplicação da norma urbana, de caráter administrativo, e a norma especifica ambiental, quanto à reserva de Área de Preservação Permanente.(MIRANDA, 2008, p. 4)

Alguns autores, especialistas no direito ambiental, indicam que houve uma ampliação dos limites de proteção ambiental criados pela Lei 6.766, de 19 de dezembro de 1979, com relação a Faixa non aedificandi de quinze metros, em razão da edição da Lei 7.511, de 7 de julho de 1986, que altera o Código Florestal aumentando para trinta metros a Área de Preservação Permanente para os rios com largura de até dez metros. (MACHADO, 2005, p. 719) 
Contudo, tendo defendemos que os conceitos de Faixa non aedificandi e Área de Preservação Permanente são materialmente distintos. O primeiro trata de edificação e planejamento urbano; o segundo, de preservação e proteção ambiental. A aplicação de um não exclui a aplicação do outro.

[...] Um parâmetro não se confunde com o outro. Embora tratem de limites de ocupação de margens de rios, o artigo segundo do Código Florestal trata da PRESERVAÇÃO de matas ciliares e demais vegetação em APP, já a Lei 6.766/79 trata, especificamente, de uso do solo para EDIFICAÇÃO urbana.

Os objetos de ambas as leis são diversos: um é ambiental o outro urbanístico. Essas duas ciências, embora com estreita correlação no meio das cidades, não espelham a mesma visão.

A Lei ambiental indica as áreas de interesse ambiental que devam ser protegidas da intervenção humana, preservando-se a vida silvestre e natural nos seus espaços, a preservação dos recursos hídricos, a estabilidade geológica e o fluxo gênico.

A Lei urbanística trata de áreas que não podem sofrer, em hipótese alguma, edificação, dentro dos critérios da engenharia civil, sendo a intenção do diploma legal garantir segurança humana na ocupação dos espaços urbanos, evitando o convívio de pessoas em áreas de instabilidade. São critérios de segurança humana na ocupação do solo, associados à critérios de melhoria da paisagem urbana e da saúde coletiva.

Ou seja, o Código Florestal trata em preservação das matas ciliares, visando a garantia das funções ambientais dos espaços e vegetação ciliar, conforme já indicado acima; A Lei de Parcelamento do Solo Urbano indica as restrições edilícias nesses espaços, visando a segurança, a saúde social e a harmonia arquitetônica nas ocupações humanas.(MIRANDA, 2008, p. 4)

$\mathrm{Na}$ atividade do projeto de urbanismo e arquitetura devemos considerar a complementaridade destes dois conceitos jurídicos em corredores verdes, formando área verdes lineares potenciais para serem utilizados numa rede ecológica contínua de proteção da vegetação, assim como de recursos naturais.(FRIEDRICH, 2007, p. 75) 
Nas cidades brasileiras, a carência de reserva de Faixa non aedificandi e Área de Preservação Permanente em áreas urbanas resultaram em vários problemas ambientais urbanos, que podemos citar: o alto grau de impermeabilização do solo provoca, nos períodos de chuva, aumento de enchentes com a ocorrência de mortes e doenças ocasionadas dessas tragédias, além dos prejuízos para economia, e, nos períodos de seca, baixa umidade do ar com aumento do número de atendimentos hospitalares devido ao acréscimo de doenças relacionadas; a massificação do uso do transporte individual motorizado colabora para a deterioração da qualidade do ar e do clima, com a formação de ilhas de calor e a ocorrência cada vez mais freqüente de variações bruscas de temperatura; a desvalorização do espaço urbano; a produção em larga escala de resíduos sólidos e efluentes que não recebem tratamento adequado, etc. (LUCAS, 2009, p. 40)

Contudo, vimos que a legislação prevê a reserva de Faixa non aedificandi e Área de Preservação Permanente, que somadas beneficiam a biota e, conseqüentemente, trazem melhorias para as áreas de saúde, economia e cultura das pessoas que vivem nas cidades.

\section{USO E OCUPAÇÃO SUSTENTÁVEL: ZONEAMENTO AMBIENTAL}

O planejamento sustentável de uma cidade deve considerar a manutenção das matas ciliares e a preservação da área de fundo de vale com devido uso apropriado, pois se sabe, o impedimento do uso do solo só deve atrair ações indesejadas, como a desobediência às leis e ocupações desordenadas, tendo em vista que a fiscalização do Poder Público não é capaz de impedir todo ato de ocupação ilegal, dada a dimensão do problema.(FRIEDRICH, 2007, p. 77)

O zoneamento urbano é um instrumento jurídico de controle e ordenação do uso e ocupação de um aglomerado humano. Através deste instrumento, o espaço urbano é classificado em territórios chamados zonas de uso, nas quais serão estabelecidas as modalidades de uso e ocupação do solo. O marco inicial do zoneamento urbano é o artigo 182, $\S 1^{\circ}$, da Constituição Federal de 1988, que determina ser competência do Plano Diretor, aprovado pela Câmara Municipal, a política de desenvolvimento e expansão urbana, em que deverá constar o projeto de ordenamento urbano, com a previsão das vias, zoneamento e espaços verdes.(MORAES, 2006, p. 73) 
Dentro dos preceitos constitucionais do artigo 225 de que "Todos têm direito ao meio ambiente ecologicamente equilibrado, bem de uso comum do povo e essencial à sadia qualidade de vida", cabe ao Poder Público defender o interesse comum de preservação e proteção do meio ambiente e como resposta a essa demanda surge um novo instrumento jurídico chamado de zoneamento ambiental urbano, que visa o controle e ordenação do uso e ocupação do ambiente urbano com especial atenção para a preservação, proteção e recuperação do equilíbrio ecológico nas cidades.

O conceito de zoneamento ambiental vai ao encontro do conceito de desenvolvimento sustentável, pois leva em consideração a escassez dos recursos naturais e a necessidade de preservação para as futuras gerações. Contudo, o zoneamento ambiental não pretende o simples ordenamento de uso e ocupação do solo da cidade, mas o alcance da qualidade de vida atingida pela utilização racional dos recursos naturais dentro de um território, classificado pelas suas peculiaridades e pelas atividades ali desenvolvidas.(MORAES, 2006, p. 73)

A figura do zoneamento ambiental amplia o conceito, porque não será mais apenas um zoneamento urbano, como instrumento que preconiza uma estrutura mais orgânica para as cidades, dado que não se limita ao ambiente destas, mas não muda a sua essência nem a sua natureza. Dá mais ênfase à proteção de áreas de significativo interesse ambiental, mas ainda assim continua a ser zoneamento de uso e ocupação do solo, sempre no interesse do bem-estar e da realização da qualidade de vida da população (SILVA, 1994, p. 181).

O zoneamento ambiental urbano vai definir a melhor forma de ocupar, de maneira sustentável, as áreas de interesse ambiental de forma a criar usos para estas áreas, qualificando urbanística e ambientalmente com equipamentos voltados à utilidade pública, conservando os recursos naturais.

As propostas de uso e ocupações do solo em áreas de fundo de vale urbanos compatíveis com os conceitos de preservação e proteção são por exemplo: a circulação não motorizada - por passeios de pavimento permeável e ciclovias - parques lineares para o lazer ativo e contemplativo, agricultura sustentável, feiras de comércio local, etc. O lazer também tem o objetivo de integrar o indivíduo ao grupo a que pertence na 
comunidade, desenvolvendo, por intermédio de iniciativas educacionais e recreativas, boas relações humanas, nas quais tenta instigar sentimentos de segurança emocional e geração de capital social.(FRIEDRICH, 2007, p. 120)

O parque linear é uma oportunidade que as cidades têm de reestruturar sua concepção a partir de novos paradigmas. A recuperação dos fundos de vale através deste instrumento estabelece uma nova lógica de valoração econômica para a cidade por meio da restauração dos seus bens ambientais e humanos. $O$ desenvolvimento sustentável das cidades é um problema recente que o Poder Público deve equacionar. A conservação ambiental só pode ocorrer mediante a planos e planejamento de uso adequado para cada região. A simples demarcação de Área de Preservação Permanente ou de Faixa non aedificandi não garante que aquele local vá cumprir sua função de preservação e proteção do ecossistema. Sabemos que a capacidade de fiscalização do meio ambiente é limitada, portanto, devemos lembrar que o artigo 225 da Constituição Federal de 1988 impôs não só ao Poder Público, mas também "à coletividade o dever de defendê-lo e preservá-lo para as presentes e futuras gerações".

\section{PARADIGMA SANITARISTA E RENATURALIZAÇÃO}

A partir de 1987, com a elaboração do Relatório de Brundtland, a introdução do conceito de desenvolvimento sustentável começou a tomar importância no planejamento das cidades que, então, passaram a considerar os aspectos ambientais. Nossos representantes no governo introduziram o componente ambiental nos seus planos e ações e, da mesma forma, a sociedade iniciou as cobranças de atitudes coerentes com o desenvolvimento sustentável.

Até então, o planejamento das cidades dificilmente se preocupava com a conservação dos recursos naturais, privilegiando o desenvolvimento econômico e a expansão territorial sem limites. Podemos dizer que os debates sobre a questão apresentam mudanças, indicando os aspectos benéficos da manutenção das características naturais dos rios, ou ao menos mais próximas delas.(LUCAS, 2009, p. 24)

A recuperação de áreas degradadas é, portanto, uma conseqüência do uso incorreto da paisagem urbana e fundamentalmente dos solos, sendo apenas uma tentativa limitada de remediar um dano que na maioria das vezes poderia ter sido evitado.(YANG, 2005, p. 12) 
No exterior, podemos citar alguns exemplos dessa mudança de paradigma. A agencia de proteção ambiental dos Estados Unidos - Environmental Protection Agency - conta com um programa específico voltado para a recuperação das áreas de várzea e sua vegetação. O país gastou mais de 15 bilhões de dólares em 30.000 projetos envolvendo restauração de rios e alagados entre 1990 e 2006.

No Japão, a partir da década de 70 surgiram os primeiros 'rios-parque aquafílicos' - parques lineares implantados sobre cursos d'água que visavam, principalmente, permitir que houvesse novamente uma familiarização das crianças com a presença de água no cenário urbano.

Houve, inclusive, a reversão na canalização de alguns córregos, com a recuperação das formas e meandros às margens dos cursos d'água e o restabelecimento das condições naturais para o crescimento da flora e fauna originais - utilizando-se para isso de materiais como pedras e estacas de madeira (visando permitir a formação de poços e correntezas necessários para alguns ecossistemas). Esse processo é conhecido como restauração ou renaturalização dos rios.

Atualmente, essa prática pode ser definida como a tendência adotada para a intervenção em rios urbanos no país, que no período entre 1991 e 2006 teria implantado mais de 23.000 projetos (LUCAS, 2009, p. 24).

Experiência semelhante foi realizada em Seul, na Coréia, com a recente renaturalização do rio Cheonggyecheon, cuja divulgação na imprensa brasileira e internacional causou interesse de especialistas em engenharia ambiental. O curso d'água, que corta a capital coreana, foi canalizado na década de 60 para a implantação de um viaduto expresso no centro da cidade. Em 2002 teve início a implantação de um projeto de renaturalização, implantado em 4 anos, envolvendo a demolição de $6 \mathrm{~km}$ de viaduto, o destamponamento e restauração do rio e o investimento em sistemas de tratamento de esgoto.(LUCAS, 2009, p. 28)

São exemplos de qualificação urbanística e ambiental, visando recuperar a qualidade de vida em área urbana, procurando o equilíbrio entre o meio ambiente natural e artificial, lembrando que não seria necessário este investimento se o principio da precaução tivesse sido empregado e a degradação ambiental não tivesse ocorrido. 
Contudo, no Brasil ainda não há experiências significativas de restauração de cursos d'água ou intervenções que rompam com o paradigma saneamento, canalização e sistema viário. Devemos lembrar, no entanto, que a adoção da concepção de recuperação, tanto da qualidade das águas quanto das várzeas dos rios urbanos, já encontra respaldo na legislação. Os projetos envolvendo a renaturalização e restaurações de margens de cursos d'água urbanas devem considerar a escala local e seus aspectos específicos, não necessariamente seguindo diretrizes de projetos bem sucedidos no exterior.(LUCAS, 2009, p. 30)

\section{SUPRESSÃo DE ÁREA DE PRESERVAÇÃO PERMANENTE}

A Constituição Federal de 1988 já previa a proteção jurídica especial às florestas de preservação permanente e às reservas florestais. Entretanto, as alterações das características destes espaços protegidos só poderiam ocorrer mediante amplo debate social que culminem em Lei.

Nem todos os espaços estão submetidos à mesma proteção jurídica. Os que gozarem de uma especial proteção - como os destinados às florestas de preservação permanente e às reservas legais florestais - só poderão ser alterados e suprimidos através de lei. Lei específica para cada caso. A Constituição não está impedindo totalmente que a lei suprima ou altere esses espaços, mas indica procedimento específico para a transformação, que é o processo legislativo. Os constituintes manifestaram a vontade do povo brasileiro de que haja maior tempo e maior discussão quando se pretenda suprimir ou alterar os espaços protegidos e seus componentes.

$\mathrm{O}$ art. $225, \S 1^{\circ}$, III, da CF, que introduziu a inovação sobre os espaços protegidos e seus componentes, não tem sido devidamente compreendido e implementado. O Poder Legislativo precisa discutir sobre um bem que está caracterizado como 'permanente'. Uma floresta de preservação permanente não é para ser suprimida ou alterada precipitadamente, a todo momento ou ao sabor do interesse somente do partido político que administre o meio ambiente.

A implementação do art. $225, \S 1^{\circ}$, III, da CF poderá acarretar certa demora na apreciação do pedido de supressão de uma floresta de preservação permanente. Contudo, é de ser ponderado que uma 
vegetação de tal importância não se elimina todos os dias. A seca que expulsa as pessoas e os desmoronamentos que matam têm como uma de suas causas o corte da vegetação de preservação permanente. $O$ processo legislativo dá chance de maior participação social para a decisão de manter ou suprimir a vegetação.

(MACHADO, 2005, p. 722)

Entretanto, o amplo debate previsto na Constituição Federal de 1988 sobre a utilização de Áreas de Preservação Permanente culminou considerando que é mais importante resolver as questões econômicas e sociais nas cidades, como o déficit habitacional, do que a conservação dos recursos naturais, com a edição da Resolução CONAMA $n^{\circ} 369$.

A Resolução CONAMA n 369 , de 28 de março de 2006 dispõe sobre os casos excepcionais que possibilitam a intervenção ou a supressão de vegetação em área de preservação permanente, definidos como: de utilidade pública, interesse social ou baixo impacto ambiental.

A resolução, em seu artigo $2^{\circ}$, inclui a regularização fundiária sustentável em área urbana como um dos casos de intervenções em área de preservação permanente que podem ser autorizadas pelo órgão ambiental por razões de interesse social.

De acordo com o artigo $4^{\circ}$, a intervenção em APP localizada em área urbana dependerá de autorização do órgão ambiental competente. Para municípios que possuam Conselho de Meio Ambiente com caráter deliberativo e Plano Diretor ou Lei de Diretrizes Urbanas, a autorização será do órgão ambiental municipal, com anuência prévia do órgão ambiental estadual. Caso contrário, a autorização será feita pelo órgão ambiental estadual.

Para obter a autorização, o requerente deve comprovar a inexistência de alternativa técnica e locacional, inexistência de risco de agravamento de enchentes e erosões (art. $3^{\circ}$ ).

No artigo $5^{\circ}$, a resolução prevê que o órgão ambiental competente estabelecerá as medidas de caráter compensatório e mitigador a serem adotadas pelo requerente. As medidas de caráter compensatório deverão ocorrer na mesma sub-bacia, preferencialmente na área de influência do empreendimento ou nas cabeceiras dos rios. 
A compensação consiste, de acordo com o artigo $4^{\circ} \S 2^{\circ}$, na recuperação ou recomposição da área de preservação permanente. (LUCAS, 2009, p. 100).

Dentro dos preceitos constitucionais do artigo 225 , a Resolução CONAMA n 369 , de 28 de março de 2006 toma importante lugar no uso e ocupação de Áreas de Preservação Permanente urbana, com força de Lei, dispondo sobre os casos que possibilitam a intervenção ou a supressão de vegetação nas mesmas. De qualquer forma, cabe lembrar que a Constituição Federal de 1988 foi clara ao determinar o principio da prevenção e precaução ao meio ambiente, que consiste em dizer que não somos responsáveis somente pelos danos ambientais que conhecemos, mas que também deveríamos duvidar, aplicando em certos casos a prevenção e a precaução, dado a incerteza do dano ambiental que pode ocorrer.(MACHADO, 2005, p. 72)

Entendemos que a supressão de Área de Preservação Permanente deve ser pensada como último recurso, pois a interferência humana neste delicado ecossistema pode levar a prejuízos ainda desconhecidos pela humanidade. O nosso planeta levou bilhões de anos para desenvolver a vida como conhecemos. Muitos aspectos dessa vida ainda estão por ser descoberto e muito pode se perder antes de ser conhecermos.

De fato, a prevenção é preceito fundamental, uma vez que os danos ambientais, na maioria das vezes, são irreversíveis e irreparáveis. Para tanto, basta pensar: como recuperar uma espécie extinta? Como erradicar os efeitos de Chernobyl? Ou, de que forma restituir uma floresta milenar que fora devastada e abrigava milhares de ecossistemas diferentes, cada um com o seu essencial papel na natureza? (FIORILLO, 2003, p. 36)

O princípio da prevenção e a precaução entendem que diante da impotência do sistema jurídico, incapaz de restabelecer, em igualdade de condições, uma situação idêntica à anterior, deve se adotar o princípio da prevenção, com medidas de precaução ao dano ambiental, como sustentáculo do direito ambiental, consubstanciando-se como objetivo fundamental do direito.(FIORILLO, 2003, p. 36) 
Assim, lembramos que nossa Constituição Federal de 1988 expressamente adotou o princípio da prevenção e a precaução, ao preceituar, no seu artigo 225 , o dever do Poder Público e da coletividade de proteger e preservar o meio ambiente para as presentes e futuras gerações.(FIORILLO, 2003, p. 37)

\section{CONSIDERAÇÕES FINAIS}

O processo de mudança de paradigma do saneamento, canalização e sistema viário às margens de rios e córregos é um fato que estamos observando hoje em muitas cidades do mundo. Trata-se de um processo lento que demanda investimento em educação ambiental para formação de pessoas conscientes de seu papel no equilíbrio do meio ambiente, que tenham condições de cobrar de suas representantes ações coerentes com os planos de desenvolvimento sustentável das cidades.

A qualificação do meio urbano pode ser feita a partir de uma nova ótica, em que o ecossistema de rios, córregos, áreas permeáveis, matas ciliares e fundos de vale são valorizados com uso e ocupação apropriado ao tipo de solo, a partir de zoneamento ambiental urbano adequado, equipamentos de lazer e cultura entre outros, ao invés de uma legislação puramente proibitiva que acaba sendo descumprida face ao fraco poder de fiscalização do Poder Público.

O desenvolvimento sustentável das cidades brasileiras, com o respeito dos ecossistemas, é uma meta tangível, sendo que, a reserva legal às margens de curso d'água urbano é prevista na forma de Faixa non aedificandi, sob a visão edilícia na forma observada pela Lei do Parcelamento do Solo Urbano; e Área de Preservação Permanente, de maneira mais ampla, sob a visão ambiental de preservação e proteção do meio ambiente, inclusive urbano, no Código Florestal.

A qualificação urbanística e ambiental com a conservação dos recursos naturais deve a meta do urbanista e do arquiteto. Historicamente, o desprezo a este fato acarretou diversos problemas com os quais convivemos hoje. Ainda há tempo para revertermos esta situação. Métodos desenvolvidos pela engenharia ambiental possibilitam a recuperação e renaturalização de margens de cursos de água urbanos, já experimentados em algumas partes do mundo com grande êxito. 
O urbanismo contemporâneo nas cidades brasileiras deve atentar para o novo conceito de salubridade em área urbana; algo como a utilização dos recursos naturais com sabedoria, com o mínimo de degradação ambiental, mantendo o equilíbrio natural dos ecossistemas, respeitando o ciclo natural de autolimpeza do meio ambiente.

\section{REFERÊNCIAS}

ABREU, Alexandre Herculano; OLIVEIRA, Rodrigo de. Regime jurídico das matas ciliares. Disponível em: <http://www.buscalegis.ccj.ufsc.br/revistas/index.php/buscalegis/article/view File/26712/26275> Acesso em 26/4/2012.

ARAÚJO, Suely Mara Vaz Guimarães de. As áreas de preservação permanente e a questão urbana. Câmara dos Deputados, Consultoria Legislativa, Anexo III - Térreo, Praça dos 3 Poderes, Brasília - DF, 2002, 12 f. Disponível em: <http://www.mp.ba.gov. br/atuacao/ceama/material/doutrinas/arborizacao/as_areas_de_preservacao_permanente_questao_urbana.pdf> Acesso em 26/4/2012.

BRASIL. O Presidente da República. VARGAS, Getulio. Decreto Federal n. 23.793, de 23 de janeiro de 1934. Approva o codigo florestal que com este baixa. Rio de Janeiro, 23 de janeiro de 1934.

. O Presidente da República. VARGAS, Getulio. Decreto Federal n. 24.643, de 10 de julho de 1934. Decreta o Código de Águas. Rio de Janeiro, 10 de julho de 1934. D.O.U. de 27/7/1934.

O Presidente da República. BRANCO, H. Castello. Lei Federal n. 4.771, de 15 de setembro de 1965. Institui o novo Código Florestal. Brasília, 15 de setembro de 1965. D.O.U. de 16/9/1965.

O Presidente da República. FIGUEIREDO, João Baptista de Oliveira. Lei Federal n. 6.766, de 19 de dezembro de 1979. Dispõe sobre o Parcelamento do Solo Urbano e dá outras Providências. Brasília, 19 de dezembro de 1979. D.O.U. de 20/12/1979. 
. O Presidente da República. SARNEY, José. Lei Federal n. 7.511, de 7 de julho de 1986. Altera dispositivos da Lei n. 4.771, de 15 de setembro de 1965, que institui o novo Código Florestal. Brasília, 7 de julho de 1986. D.O.U. de 8/7/1986.

. O Presidente da República. GUIMARÃES, Ulysses. Constituição Federal. Brasília, 5 de outubro de 1988.

. O Presidente da República. SARNEY, José. Lei Federal n. 7.803, de 18 de julho de 1989. Altera dispositivos da Lei n. 4.771, de 15 de setembro de 1965, e revoga as Leis n. 6.535, de 15 de junho de 1978, e 7.511, de 7 de julho de 1986. Brasília, 18 de julho de 1989. D.O.U. de 20/7/1989.

. O Presidente da República. CARDOSO, Fernando Henrique. Medida Provisória Federal n. 2.166-67, de 24 de agosto de 2001. Altera os arts. $1^{\circ}, 4^{\circ}, 14,16$ e 44, e acresce dispositivos à Lei n. 4.771, de 15 de setembro de 1965, que institui o novo Código Florestal, bem como altera o art. 10 da Lei $n$. 9.393, de 19 de dezembro de 1996, que dispõe sobre o Imposto sobre a Propriedade Territorial Rural ITR, e dá outras providências. Brasília, 24 de agosto de 2001. D.O.U. de 25/8/2001.

CARVALHO, Carlos Gomes de. Dicionário jurídico do ambiente. 2. ed. São Paulo: Letras, 2002. $359 \mathrm{p}$.

CONAMA. Presidente do Conselho. CARVALHO, José Carlos. Resolução n. 302, de 20 de março de 2002. D.O.U. 13/5/2002.

Presidente do Conselho. CARVALHO, José Carlos. Resolução n. 303, de 20 de março de 2002. D.O.U. 13/5/2002.

. Presidente do Conselho. SILVA, Marina. Resolução n. 369, de 28 de março de 2006. D.O.U. 29/3/2006.

DIAS, Genebaldo Freire. Educação Ambiental: princípios e práticas. 9. ed. São Paulo: Gaia, 2004. 551 p.

FARIA, Ernesto. Dicionários Garnier. Vocabulário latino-português: significação e história das palavras, agrupadas por famílias, segundo os programas atuais. Belo Horizonte: Líthera Maciel, 2001. v. 8. 443 p. 
FIORILLO, Celso Antonio Pacheco. Curso de direito ambiental brasileiro. 4. ed. São Paulo: Saraiva, 2003. 404 p.

FRANCO, Maria de Assunção Ribeiro. Desenho Ambiental: Uma Introdução à Arquitetura de Paisagem com o Paradigma Ecológico. São Paulo: Annablume: Fapesp, 1997. 224 p.

FRIEDRICH, Daniela. O parque linear como instrumento de planejamento e gestão das áreas de fundo de vale urbanas. Porto Alegre, 2007. 273 p. Dissertação (Mestre em planejamento urbano e regional) - Faculdade de Arquitetura, Universidade Federal do Rio Grande do Sul.

HOUAISS, Antônio; VILLAR, Mauro de Salles; Instituto Antônio Houaiss de Lexicografia e Banco de Dados da Língua Portuguesa S/C Ltda. Dicionário Houaiss Da Língua Portuguesa. Rio de Janeiro: Objetiva, 2001. 2925p.

LUCAS, Renata Paula. O código florestal em meio urbano: implicações da aplicação da lei $n^{\circ} 7.803 / 89$ na regularização de assentamentos irregulares em grandes cidades. São Paulo, 2009, 160 p. Dissertação (Mestrado na área de Hábitat) - Faculdade de Arquitetura e Urbanismo, Universidade de São Paulo.

MACHADO, Paulo Affonso Leme. Direito ambiental brasileiro. 13. ed. São Paulo: Malheiros Editores, 2005. $1096 \mathrm{p}$.

MIRANDA, Anaiza Helena Malhardes. APP em área urbana consolidada. In: IRIB boletim eletrônico. São Paulo, ano VIII, 23 de janeiro de 2008. Disponível em: <http:// www.mp.go.gov.br/portalweb/hp/9/docs/app_em_area_urbana_consolidada.pdf $>$ Acesso em 26/4/2012.

MORAES, Luís Carlos Silva de. Curso de direito ambiental. 2. ed. São Paulo: Atlas, 2006. $270 \mathrm{p}$.

SILVA, José Afonso da. Direito ambiental constitucional. São Paulo: Malheiros, 1994. $352 \mathrm{p}$. 
YANG, Abner. Degradação do Rio Tietê na cidade de são Paulo, com ênfase para a fisionomia da mata ciliar. São Paulo, 2005. 43 p. Trabalho de Conclusão de Curso (Bacharel em Ciências Biológicas) - Departamento de Ciências da Saúde, Centro Universitário Nove de Julho. 